
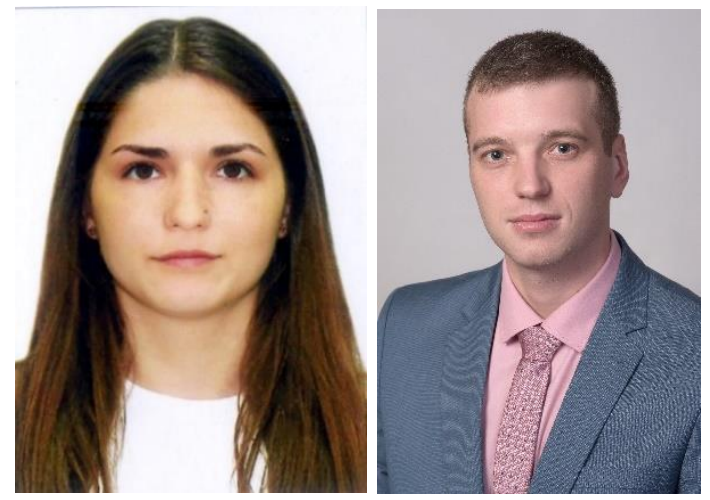

\section{БИОМЕТРИЧЕСКИЕ ПОКАЗАТЕЛИ ГАЗОННЫХ ТРАВ ПРИ ВЫРАЩИВАНИИ ИХ В ОБРАБОТАННОЙ ГЛИНОЙ КЕЛЛОВЕЯ ПОЧВЕ}

\author{
Г. И. Смицкая, студентка, \\ e-mail: budakovag@mail.ru \\ ФГБОУ ВО «Курский государственный университет»
}

Н. П. Неведров, канд. биол. наук, доц., e-mail: 9202635354@mail.ru

ФГБОУ ВО «Курский государственный университет»

В работе изложены данные о влиянии применения технологий детоксикации загрязненных тяжелыми металлами почв на биометрические показатели газонных трав. Выявлено, что глина келловея при низком уровне загрязнения почвы (1,5 ПДК) приводит к снижению концентрации подвижного свинца в урбаноземе до экологически безопасных значений (с 14,7 до 2,5 мг/кг). Отмечено, что глина келловея оказывает неоднозначное влияние на продукцию биомассы у растений газонных трав и зависит от дозы внесения. Установлено, что загрязнение урбанозема свинцом приводит к уменьшению количества устьиц у газонных трав. Обнаружено, что во всех вариантах опыта вне зависимости от дозы внесения глины келловея в почву наблюдалось повышение показателя зольности на 4,7-54,5\%. Выявлено, что обработка почвы глиной келловея положительно влияет на формирование почвенной структуры.

Ключевые слова: газонная трава, глина келловея, удобрение-сорбент, тяжелые металль, свинеи, урбаноземь

\title{
ВВЕДЕНИЕ
}

На сегодняшний день загрязнение почв тяжелыми металлами (ТМ) является одной из важнейших экологических проблем. В большей степени данная проблема касается городских почв, где под антропогенным воздействием происходит интенсивное преобразование почвенного покрова. Результаты исследований за последние пять лет показали, что в почвах Сеймского административного округа г. Курска концентрация валовых форм тяжелых металлов (свинец, цинк, медь, кадмий) повысилась на 13-34 \% [2] и подвижность их резко увеличивается.

При повышении подвижности тяжелых металлов создается угроза загрязнения сопредельных природных компонентов окружающей среды и под их воздействием происходит угнетение роста и развития растительных ассоциаций $[4,5]$.

Газоны составляют зеленую инфраструктуру любой городской территории, так как могут широко использоваться в общем ландшафтно-декоративном оформлении парков и садов, служат основой для размещения декоративной и древесно-кустарниковой растительности, в том числе могут самостоятельно оформлять территории.

Вегетация в загрязненных тяжелыми металлами почвах или грунтах делает газонные экосистемы не совсем привлекательными, приводит к потере их эстетичности. Применение технологий детоксикации загрязненных тяжелыми металлами почв позволит повысить экологическую устойчивость почв и приведет к снижению риска возникновения стрессреакции у газонных растений. 


\section{ОБЪЕКТЫ ИССЛЕДОВАНИЯ}

Объектами исследования являлись газонные растения - набор семян злаковых культур: райграс пастбищный (Lolium perenne L.), овсяница луговая (Festuca pratensis Huds.), овсяница красная (Festuca rubra L.), мятлик луговой (Poa pratensis L.), а также загрязненные свинцом городские почвы (урбанозем собственно на основе чернозема выщелоченного среднесуглинистого).

\section{ЦЕЛЬ И ЗАДАЧИ ИССЛЕДОВАНИЯ}

Цель исследования состояла в изучении влияния глины келловея на биометрические показатели газонных трав при их выращивании в загрязненных свинцом почвах.

Для реализации поставленной цели были определены следующие задачи:

1. Изучить влияние обработки почв удобрением-сорбентом (в различных дозах) и загрязнения почвы свинцом на длину проростков газонных трав.

2. Выявить влияние обработки почв удобрением-сорбентом (в различных дозах) и загрязнения почвы свинцом на продукцию биомассы надземных органов газонных трав.

3. Определить зависимость количества сформированных устьиц на листовых пластинках газонных трав от загрязнения почв свинцом и обработки почв удобрениемсорбентом.

4. Проанализировать зависимость показателя зольности от загрязнения почв свинцом и обработки почв удобрением-сорбентом.

5. Выявить зависимость показателя водопрочности структурных почвенных агрегатов от загрязнения почв свинцом и обработки почв удобрением-сорбентом.

\section{МЕТОДЫ ИССЛЕДОВАНИЯ}

Исследование проводилось в лабораторных условиях на базе научноисследовательской лаборатории экомониторинга ФГБОУ ВО «Курский государственный университет». Техногенно загрязненный урбанозем на основе чернозема выщелоченного среднесуглинистого, отобранный в промышленной зоне южной части г. Курска, имел следующие свойства: содержание гумуса $-2,6 \%, \mathrm{pH}_{(\kappa \mathrm{Cl})}-7,1, \mathrm{P}_{2} \mathrm{O}_{5}$ подвижн. -103 мг/кг, $\mathrm{K}_{2} \mathrm{O}$ подвижн. $-126, \mathrm{~N}_{\text {щ.. }}$ - 49 мг/кг. Для проведения опыта использовались вегетационные сосуды $40 \times 20 \times 10 \mathrm{~cm}^{3}$, в которые помещалось по 5 кг почвы. Исследовалось две дозы загрязнения урбанозема свинцом: в первом случае содержание валового $\mathrm{Pb}$ составляло 80,8 мг/кг (2,5 ПДК), во втором - 46,5 мг/кг (1,5 ПДК). В почвы равномерно вносилась (путем перемешивания с почвой) по 30 и 45 г/сосуд глины келловея предварительно измельченной на мельнице до тонкодисперсной пылеватой фракции. В качестве контроля использовался незагрязненный и необработанный сорбентом чернозем выщелоченный, имеющий сопоставимые химические свойства, отобранный в пригороде на юге Курска. Опыт проводился в трехкратной повторности. После обработки почв глиной келловея проводился высев семян газонных трав, которые произрастали в течение месяца. У растений учитывались изменения в анатомической структуре листа: число устьиц на единицу поверхности пластинки. Среди морфологических показателей рассматривались: длина проростков, сырая и сухая биомасса надземных органов. А также учитывались показатели зольности растений и водопрочности почвенных агрегатов.

\section{РЕЗУЛЬТАТЫ ИССЛЕДОВАНИЯ}

Результаты исследований по влиянию удобрения-сорбента на основе глины келловея на морфометрические показатели (длину проростка) показали, что при обработке почвы глиной келловея в дозе 6 г глины на 1 кг почвы, как правило, происходит стимулирование роста исследуемых газонных трав на 8,7-8,9\%. Такой эффект отмечался в вариантах опыта «Контроль + глина» и «Pb 2,5 ПДК + глина», относительно вариантов «Контроль» и «P 2,5 ПДК» соответственно (рис. 1). 


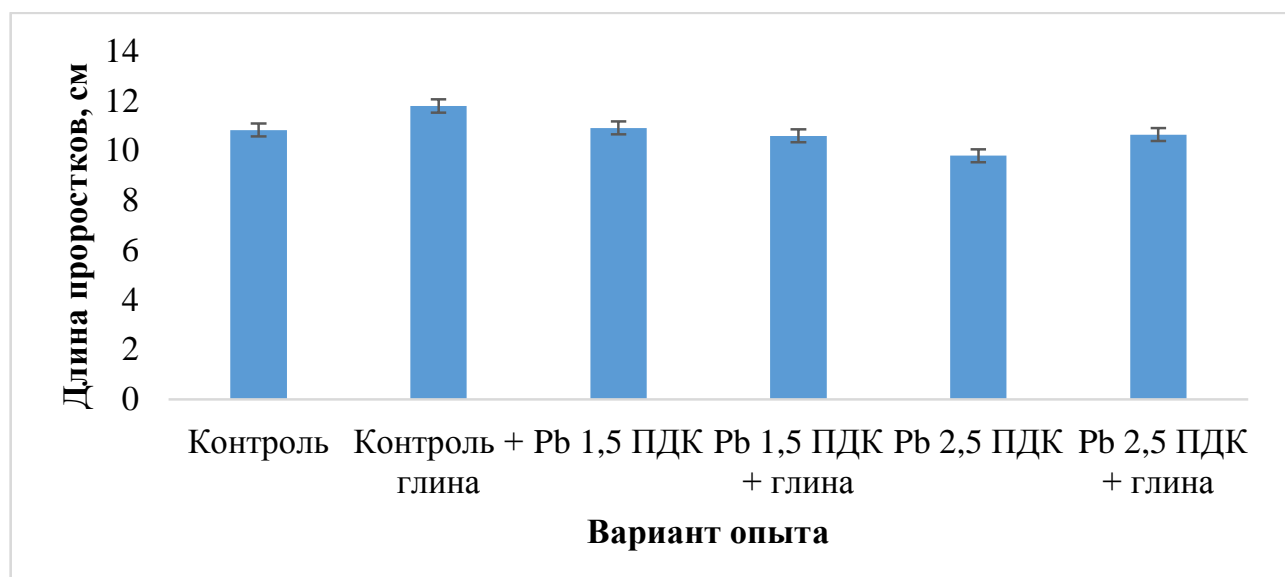

Рисунок 1 - Влияние обработки почв удобрением-сорбентом (в дозе 6 г/кг почвы) и загрязнения почвы свинцом на длину проростков газонных трав

При увеличении дозы вносимого в почву удобрения-сорбента до 9 г/кг почвы во всех без исключения вариантах опыта отмечалось значимое увеличение длины газонных трав от 4,4 до $8,4 \%$ (рис. 2).

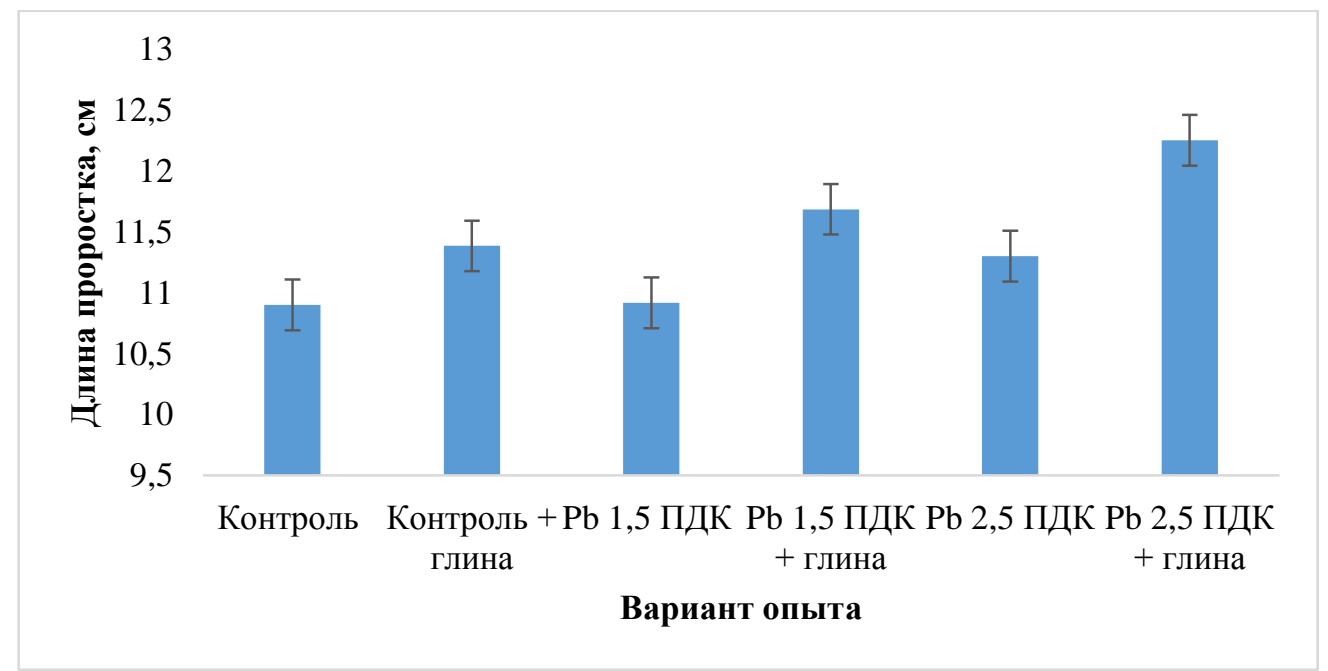

Рисунок 2 - Влияние обработки почв удобрением-сорбентом (в дозе 9 г/кг почвы) и загрязнения почвы свинцом на длину проростков газонных трав

Увеличение ростовых показателей газонных трав можно объяснить как снижением токсичности свинца в почве, так и повышением доступных форм элементов минерального питания, внесенных в составе удобрения сорбента (глины келловея).

Результаты анализа продукции газонными травами биомассы в условиях обработки удобрением-сорбентом загрязненных свинцом почв были несколько противоречивы и зависели от дозы вносимого удобрения сорбента. Так, доза удобрения-сорбента 6 г/кг почвы в вариантах опыта с загрязнением почвы свинцом (1,5 и 2,5 ПДК) приводила к увеличению сырой биомассы газонных трав на 20,3-36,0 \% и сухой - на 25,0-31,0 \% (рис. 3). 


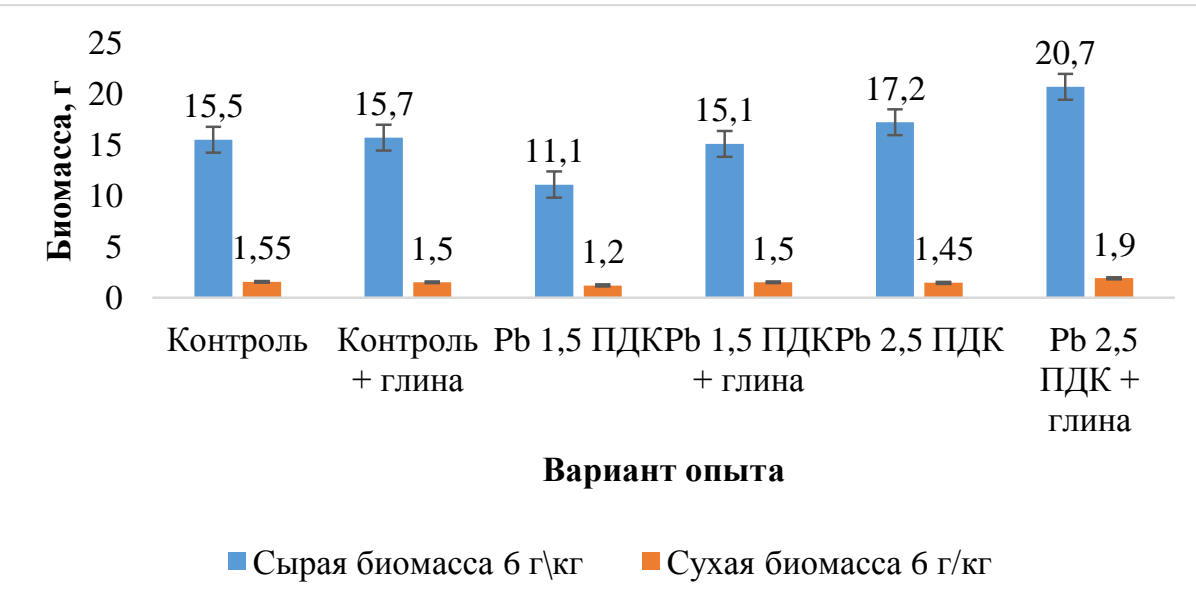

Рисунок 3 - Влияние обработки почв удобрением-сорбентом (в дозе 6 г/кг почвы) и загрязнения почвы свинцом на продукцию биомассы надземных органов газонных трав

При увеличении дозы вносимой глины келловея до 9 г на 1 кг почвы происходило снижение темпов продукции биомассы у растений газонных трав (рис. 4).

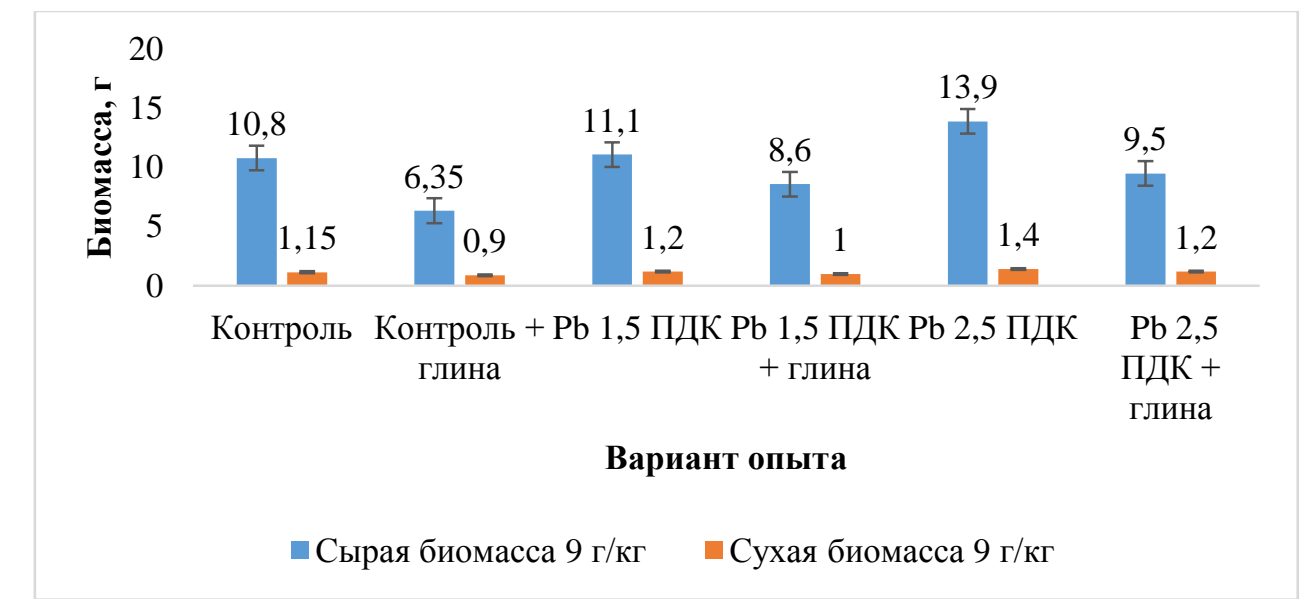

Рисунок 4 - Влияние обработки почв удобрением-сорбентом (в дозе 9 г/кг почвы) и загрязнения почвы свинцом на продукцию биомассы надземных органов газонных трав

Во всех вариантах опыта наблюдалось уменьшение значений показателя сырой биомассы на 22,5-42,1 \%, сухой - на 14,3-21,7 \%, что может быть связано с перебором количества элементов минерального питания, вносимых в почву в составе сорбента. Это можно также подтвердить стремительным ростом растений в длину при дозе глины 9 г/кг, в результате чего возникли отклонения в морфометрическом отношении длины листовой пластинки газонных трав к ширине. Также значимо снизились показатели сырой (в 2,22,5 раза) и сухой (на 3,4-36,8 \%) массы в вариантах опыта с применением дозы 9 г/кг относительно вариантов опыта с обработкой почв дозой глины 6 г/кг (рис. 3, 4).

При исследовании анатомических параметров листа, а именно при микроскопировании клеточной структуры эпидермиса листовых пластинок, отметили, что загрязнение «урбанозема собственно» свинцом в дозах 1,5 - 2,5 ПДК значимо не влияло на количество сформированных устьичных аппаратов в эпидермисе листовых пластинок исследуемых газонных трав (рис. 5). 


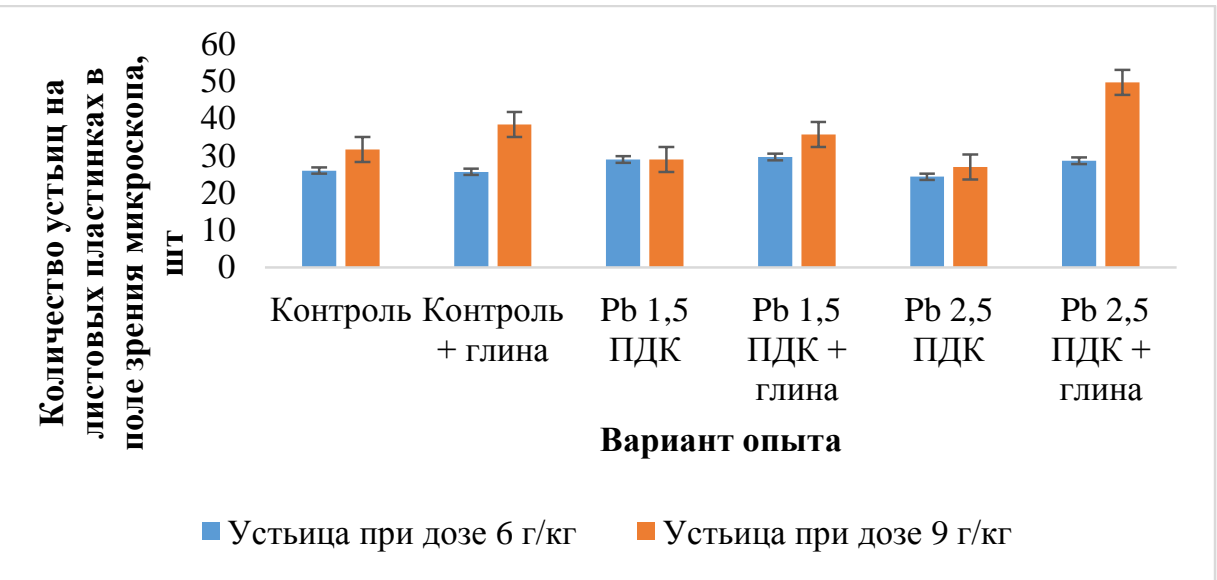

Рисунок 5 - Зависимость количества сформированных устьиц на листовых пластинках газонных трав от загрязнения почв свинцом и обработки почв удобрением-сорбентом (в дозах 6 и 9 г/кг почвы)

Тем временем обработка почв глиной келловея способствовала формированию большего количества устьиц на единицу площади листовой пластинки. Особенно отчетливо это проявлялось при обработке почвы удобрением сорбентом в дозе 9 г/кг почвы. В незагрязненной почве (Контроль) внесение глины келловея приводило к увеличению количества устьиц на единицу площади на 21,2%. При внесении глины келловея в загрязненную свинцом почву дозой 1,5 ПДК количество устьиц возрастало на 22,7 \% по сравнению с вариантом опыта « $\mathrm{Pb} 1,5$ ПДК». В варианте опыта с загрязнением почвы свинцом дозой 2,5 ПДК после внесения глины келловея количество устьиц на единицу площади листа увеличивалось на 83,7 \% по сравнению с необработанной загрязненной почвой - вариант « $\mathrm{Pb} 2,5$ ПДК». Это явления связано с запуском механизмов повышения транспирации и газообмена при действии стресс-фактора, которым, по-видимому, являлась избыточная доза удобрения-сорбента.

При дозе вносимого удобрения-сорбента 6 г/кг почвы количество устьиц статистически значимо не изменялось, за исключением варианта с дозой загрязнения «урбанозема собственно» 2,5 ПДК, где обработка почвы глиной келловея приводила к увеличению количества устьиц на единицу площади листа на 17,7 \%. Это еще раз доказывает положительное действие удобрения-сорбента, приводящее к стимулированию газообмена и транспирации в растениях газонных трав на данных стадиях онтогенеза (прорастание и рост проростка (1-й и 2-й настоящий листы)).

Поступление элементов минерального питания и ионов свинца в ткани надземных органов оценивали по косвенному показателю - зольности (доле зольных элементов в абсолютно-сухой массе надземных органов). Загрязнение почвы свинцом приводило к снижению показателя зольности на 15,4 \% в вариантах опыта «Pb 1,5 ПДК» и «Pb 2,5 ПДК» относительно незагрязненной почвы («Контроль»), что связано с нарушением физиологических и биохимических процессов, вызванных поступлением токсичных ионов в клетки растений (рис. 6).

Во всех вариантах опыта вне зависимости от дозы внесения глины келловея в почву наблюдалось повышение показателя зольности на 4,7-54,5 \%. Максимального значения исследуемый показатель достигал в варианте опыта « $\mathrm{Pb} 2,5+$ глина» - 28-34 \%. Увеличение доли зольного остатка указывает на интенсификацию потребления и накопления растениями элементов минерального питания. Важной особенностью является то, что этот эффект наблюдался только в условиях загрязнения почв свинцом. Такой эффект необходимо учитывать при разработке мероприятий по фиторемедиации почв. 


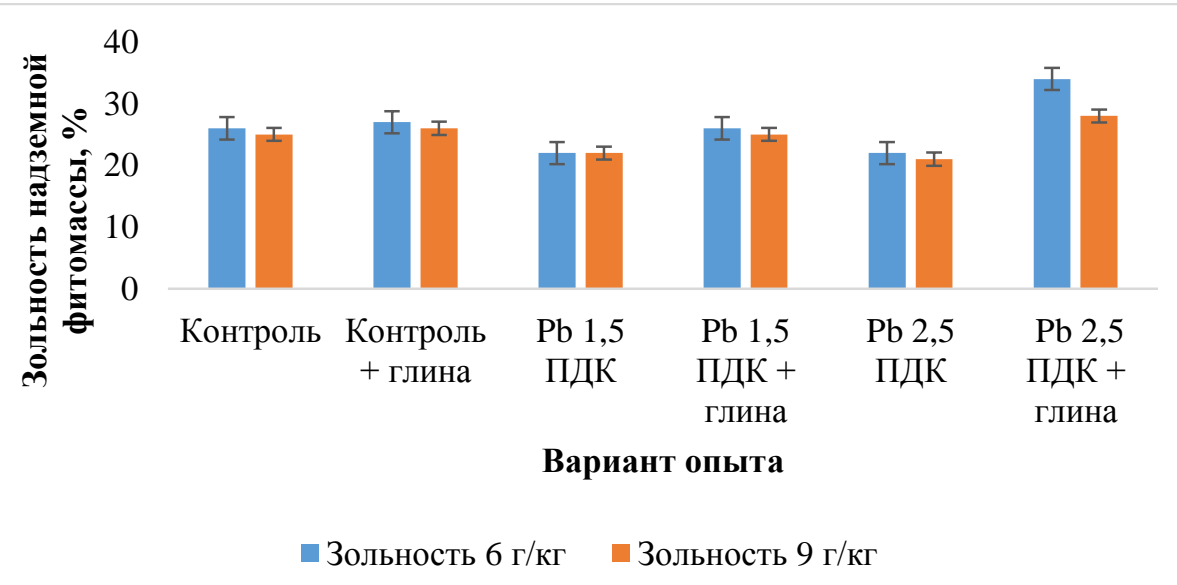

Рисунок 6 - Зависимость показателя зольности от загрязнения почв свинцом и обработки почв удобрением-сорбентом (в дозах 6 и 9 г/кг почвы)

Способность почвы обеспечивать растения всеми необходимыми факторами жизни в значительной степени зависит от ее физических свойств, среди которых особенно важное значение принадлежит структуре почвы, оказывающей существенное влияние на строение, плотность, водный, воздушный и тепловой режимы, которые, в свою очередь, оказывают воздействие на протекающие в почве микробиологические, физико-химические и другие процессы, а в конечном итоге структурная почва обеспечивает достойные условия для роста и развития растений. Хорошо оструктуренная почва лучше противостоит разрушительной силе эрозии, уменьшая поверхностный сток дождевых и талых вод, повышая ветроустойчивость ее поверхности [2]. С агрономической точки зрения важен процесс стабилизации почвенных агрегатов, который определяется химическими и биологическими факторами. К химическим факторам, способным скреплять структурные агрегаты почвы вместе, относятся: активное (молодое) органическое вещество почвы, глина, алюминий, железо и кальций. По Голдштайну и Боинчану (2000), структура почвы является функцией содержания активного органического вещества почвы, которое удерживает почвенные структурные агрегаты вместе.

Влияние удобрения-сорбента на агрофизические свойства «урбанозема собственно» нами оценивалось по показателю водопрочности структурных агрегатов, которую определяли по методу П. И. Андрианова [3].

При внесении 6 г/кг глины келловея в загрязненный урбанозем дозой свинца 2,5 ПДК установили, что количество водопрочных агрегатов после обработки почвы глиной повысилось с 54,7 до 71,8 \%.

Использование дозы глины келловея 9 г/кг также оказывало положительное структурообразующее воздействие на исследуемый «урбанозем собственно» и во всех вариантах опыта приводило к значимому увеличению содержания в почве водопрочных агрегатов - на 6,7-10,3\% (рис. 7).

Такое структурообразующее воздействие глины келловея в первую очередь обусловлено ее химическим составом. Глина келловея содержит до 4,1 \% органического вещества и 4,57\% $\mathrm{Fe}_{2} \mathrm{O}_{3}$.

Стоит отметить, что загрязнение урбанозема свинцом в дозах 1,5-2,5 ПДК не влияло на показатель водопрочности структурных агрегатов. 


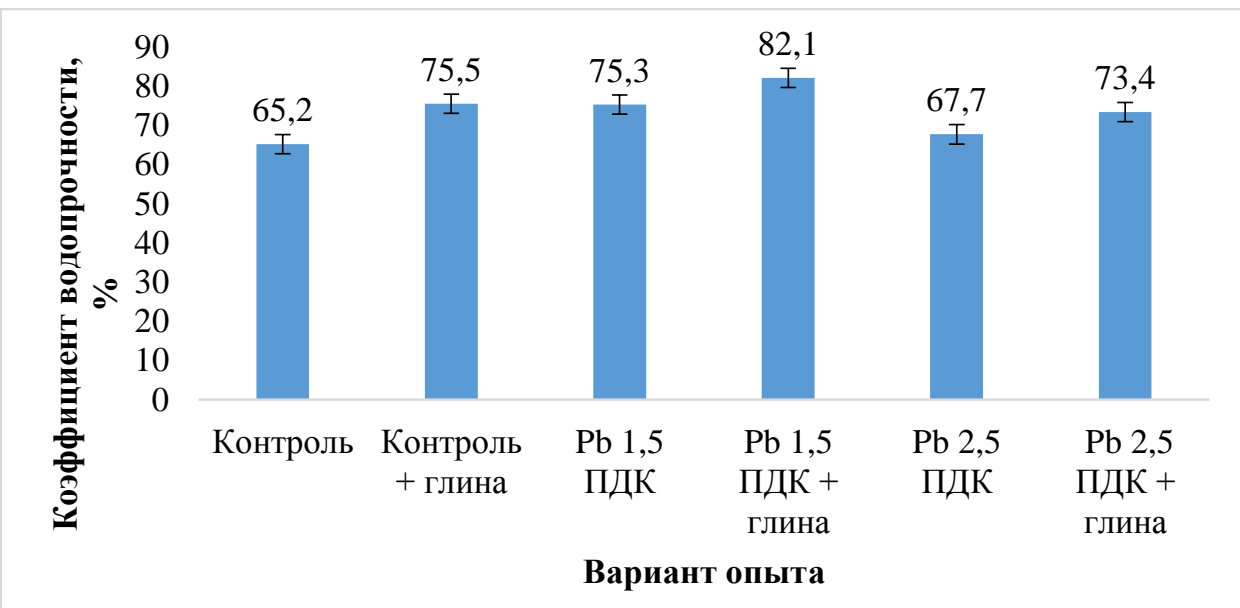

Рисунок 7 - Зависимость показателя водопрочности структурных почвенных агрегатов от загрязнения почв свинцом и обработки почв удобрением-сорбентом (в дозах 6 и 9 г/кг почвы)

\section{ЗАКЛЮЧЕНИЕ}

Таким образом, применение дозы глины келловея 6 г/кг при уровне загрязнения 1,5 ПДК почвы приводит к снижению концентрации подвижного свинца в урбаноземе до значений, не превышающих ПДК - с 14,7 до 2,5 мг/кг (5,4 раза), т. е. в этом случае за счет глины келловея можно добиться полной детоксикации почвы.

Обработка глиной келловея загрязненных свинцом почв оказывает неоднозначное влияние на продукцию газонными травами биомассы. При высокой дозе внесения глины келловея (9 г/кг почвы) темпы продукции биомассы у растений газонных трав снижаются, но при обработке почв удобрением-сорбентом в дозе 6 г/кг почвы удается увеличить сырую биомассу газонных трав до 36,0 \%, а сухую биомассу до $31,0 \%$.

Загрязнение урбанозема свинцом приводит к уменьшению количества устьиц у газонных трав (злаковых). Внесение удобрения-сорбента в загрязненный свинцом урбанозем позволяет повысить эффективность газообмена и транспирации газонных трав злаковых культур в 2-3,3 раза.

Загрязнение почвы свинцом приводит к снижению показателя зольности на 15,4\% («Pb 1,5 ПДК» и «Рb 2,5 ПДК») относительно незагрязненной почвы («Контроль»). Во всех вариантах опыта вне зависимости от дозы внесения глины келловея в почву наблюдалось повышение показателя зольности на 4,7-54,5 \%. Максимального значения исследуемый показатель достигал в варианте опыта «Pb 2,5 + глина»-28-34 \%.

Обработка почвы глиной келловея положительно влияет на формирование почвенной структуры. Применение глины в дозе 6 г/кг почвы повышает водопрочность агрегатов на $17,1 \%$, при обработке дозой 9 г/кг во всех вариантах опыта происходит значимое увеличение содержания в почве водопрочных агрегатов на 6,7-10,3\%.

Работа выполнена при поддержке гранта Фонда содействия инновациям, программа «УМНИК», договор (соглашение) № 15096ГУ/2020.

\section{СПИСОК ЛИТЕРАТУРЫ}

1. Вильямс, В. Р. Почвоведение. Земледелие с основами почвоведения / В. Р. Вильямс. Москва: Сельхозгиз, 1939. - 447 с.

2. Неведров, Н. П. Закономерности распределения валовых и подвижных форм тяжелых металлов в почвах Курской агломерации / Н. П. Неведров // Управление питанием растений и почвенным плодородием // Междунар. науч.-практ. конф., посвящ. 100-летию со дня рождения А. А. Каликинского / Белорусская государственная сельскохозяйственная академия; ред. кол. И. Р. Вильдфлуш (отв. ред.) [и др.]: материалы. - Горки, 2016. - С. 90-94. 
3. Почвы Башкортостана. Т.1: Эколого-генетическая и агропроизводственная характеристика / под ред. Ф. Х. Хазиев). - Гилем, 1995. - 385 с.

4. Angelone M., Armiento G., Cinti D., Somma R., Trocciola A. Platinum and heavy metal concentration levels in urban soils of Naples (Italy) // Fresenius Environmental Bulletin. 2002. V. 11. P. 432-436.

5. Iqbal N., Masood A., Iqbal R., Khan M., Syeed S., Khan N. A. Cadmium toxicity in plants and role of mineral nutrients in its alleviation // Amer. J. Plant Sci., - 2012. - Vol. 3. 1476-1489 p.

\title{
BIOMETRIC INDICATORS OF LAWN GRASSES WHEN GROWN IN THE SOIL TREATED WITH KELLOWAY CLAY
}

\author{
G. I. Smitskaya, student, \\ e-mail: budakovag@mail.ru \\ Kursk state university \\ N. P. Nevedrov, PhD, Associate Professor, \\ e-mail: 9202635354@mail.ru \\ Kursk state university
}

The paper presents data on the impact of the use of technologies for detoxification of soils contaminated with heavy metals on the biometric indicators of lawn grasses. It was found that the use of a fertilizer-sorbent based on Kelloway clay at the level of contamination of 1.5 MPC of the soil leads to a decrease in the concentration of mobile lead in urbanozem to values not exceeding the MPC - from 14.7 to $2.5 \mathrm{mg} / \mathrm{kg}$ (5.4 times). It is noted that the Kelloway clay has an ambiguous effect on the biomass production of lawn grass plants and depends on the application dose. It was found that the contamination of urbanozem with lead leads to a decrease in the number of stomata in lawn grasses. It was found that in all variants of the experiment, regardless of the dose of application of Kelloway clay to the soil, an increase in the ash content was observed by 4.7-54.5\%. It is revealed that the treatment of the soil with the clay of the Kellovei has a positive effect on the formation of the soil structure.

Keywords: lawn grass, clay callovian, fertilizer is a sorbent, heavy metals, plumbum, urbanozem 